\title{
Teaching Method for Non-technical Adult Learners to Gain an Authentic Understanding of AI Within a Day
}

\author{
Keisuke Seya *, Nobuyuki Kobayashi ${ }^{\dagger}$, Seiko Shirasaka *
}

\begin{abstract}
This study proposes and evaluates an effective teaching method for non-technical adults who want to gain an authentic understanding of artificial intelligence (AI) within a short time budget. Recent studies have revealed the existence of non-technical business professionals who want to improve their participation in technical discussions and identified their needs for learning technologies effectively using real programming tools. The proposed teaching method utilizes the story aligned with the history of AI, visual feedback, and agile practices to overcome the challenges the non-technical adults face. In this study, we evaluated the effectiveness of the proposed teaching method by the open coding method and by the paired t-test over the responses to the questions based on the expectancy-value theory before and after the lecture. We found that this teaching method effectively supported the learners to understand the core technical concepts of AI using authentic tools within a day. We also confirmed that the non-technical adult learners had significantly changed their attitude from initially negative to positive in terms of expected success and value in understanding AI, which is one of the essential outcomes for the learners as they predict the learner's performance on understanding $\mathrm{AI}$ in the future.

Keywords: adult learners, technology education, programming, storytelling, visual method, agile method, artificial intelligence
\end{abstract}

\section{Introduction}

Recent studies have revealed the existence of conversational programmers that represent a class of non-technical adults who are not required to write programming code in the job but try to learn programming [1][2][3] to improve their participation in technical conversations and to increase their value in the labor market. Unfortunately, most of the existing learning recourses for studying programming are not designed for them but designed for technical people or for young school students who are technical professional candidates. Therefore, to find effective teaching methods optimized for conversational programmers is identified to be one of the research areas to address their needs [3].

\footnotetext{
* Graduate School of System Design and Management, Keio University, Kanagawa, Japan

$\dagger$ The System Design and Management Research Institute of Graduate School of System Design and Management, Keio University, Kanagawa, Japan
} 
The purpose of this study is to propose the use of stories, visual feedback, and agile teaching method for non-technical adult learners who want to gain an authentic understanding of AI within a short time budget. In order to mitigate the failures of business professionals in learning technologies, this study worked on the following issues. First, non-technical adults might not be able to understand programming at all [4]. Second, it becomes difficult to understand concepts and mathematical equations if learners cannot implement them [5]. Third, learners might lose their learning motivation if they cannot complete the given tasks [6].

The novelty of this study is that we found the fact that non-technical adult learners can go through the lecture with the authentic programming tools and change their expectation of success in understanding AI within a short time budget. The proposed method not only changed a learner's attitude from negative to positive but also promoted their interest in learning AI without affecting their feeling about the utility value of the learning subject.

Section 2 summarizes the related works. Section 3 explains the proposed methods to solve the three issues. Section 4 provides the evaluation method of the proposed method and the results. Section 5 discusses the results. Section 6 concludes with future research topics.

\section{Related Works}

The use of a computer in education has been conducted by many researchers since Alan J. Perlis first suggested [7] that every university student should study computer science in 1961 . However, most of the studies have been done with young students in the classroom [8] and not for the nontechnical adults who try to gain an authentic understanding of the latest technologies.

\subsection{Using programming to learn other subjects}

Even though it has been argued for a long time if learning programming or computational thinking develop knowledge transfer on the other subjects [9][10], there is little evidence to believe learning programming yields such knowledge transfer. On the other hand, there are several studies that show the benefit of programming as a medium when it is used to teach other science subjects [11][12]. For example, a case study showed the effectiveness of the use of programming to teach Physics by demonstrating students' good understanding of the meaning of Physics equations [13]. This method (i.e., using programming to learn other subjects) might work effectively to meet the goal of conversational programmers too. However, there is no study that has validated if this method works for non-technical adult learners yet.

\subsection{Finding the link between concept and its implementation}

The link between a high-level abstract concept and its low-level implementation done by programming is hard to conceive [5]. An attempt to show such a link is tried in Kobayashi's study [14]. In this study, the top-level concept and the implementation level elements are connected by the conceptual diagram using Goal Structuring Notation (GSN) [15], and it was provided to the learners upfront. Since the link between the top-level concept and low-level implementations was given through GSN, the students did not have to find the relationship between them by themselves. The problem with this method is that students lose the opportunity to find the relationship between high-level concepts and its low-level implementation unless they do not create GSN by themselves. 


\subsection{Agile teaching method}

The agile method was born in 2001 with Agile manifesto [16] and practices in the context of software development. One of the essences of the agile method is the flexible attitude toward the unknown future. The agile method promotes the behavior of many small trials to find the right way to solve problems. If learners are unsure if they understand the learning objectives correctly, they can try their thoughts and correct it if it happens to be wrong. This process is very similar to the process proposed in the agile method as the agile manifesto says it is a good practice to find the working solution by doing.

\section{Proposed Method}

In order to make non-technical adult learners feel that they gain an authentic understanding of AI or engender reasonable expectation of success in learning AI, the proposed teaching method uses authentic tools and environment which professionals use. Learners are going to experience the authentic process and build a neural network by themselves by the end of the lecture.

To achieve the goal of this teaching method, we challenged to overcome three issues, (1) NonTechnical adults might not be able to understand programming at all. (2) It becomes difficult to understand concepts and mathematical equations if learners cannot implement them. (3) Learners might lose their learning motivation if they cannot complete the given tasks. We discuss each method which we deployed to solve these issues.

\subsection{Learning programming through real-life stories and the history of AI}

Adult learners often ask for the reasons why they need to learn the topics given to them. The use of the history of AI as the base storyline (Figure 1) helps the adult learners to understand the reasons behind the technology by knowing not only the final form of the technology but also the problems the technology had to overcome in the past like the down arrows on Figure 1. Due to the limited learning time of a typical adult learner, the scope of AI topics covered in Figure 1 is limited to those topics needed to understand and build a handwritten numerical classification code from scratch.

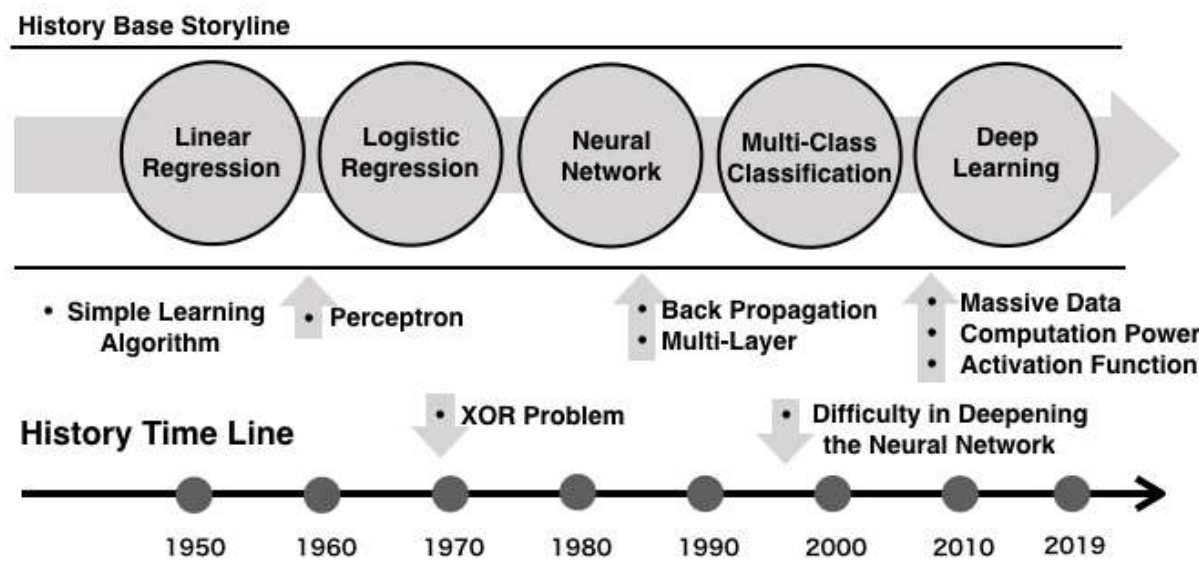

Figure 1. History of AI (adapted from Seya et al. [17]) 
Also, adult learners have more real-life experiences than young students at school. For example, we could assume that adults have tax pay experience in real life. Figure 2 is a code example of calculating tax. It is highly possible for the learners to guess what is written in the code correctly because the learners can associate their real experience of paying tax. We tried to resolve the first issue, "The non-technical adults might not be able to understand programming at all."

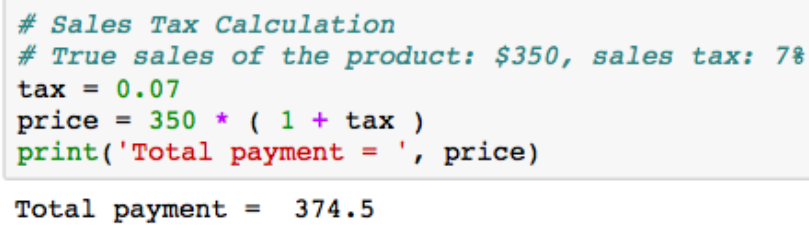

Figure 2: Code with a real story

\subsection{Implementation of concepts with the help of visual clues}

Unfortunately, it is not easy to use a real-life story as a metaphor to explain highly abstracted mathematical concepts and algorithms. Moreover, there are several ways to implement such concepts and algorithms. Therefore, it is difficult for a novice programmer to implement them from scratch. In order to cope with this type of difficulty, we propose to prepare uncompleted implementations and let the learners fill the blanks to complete the implementation. With this method, the uncompleted implementations are prepared with the visual clues between the abstract concept and its implementation to help the learners find the link between them by themselves. Figure 3 is an example of the mathematical algorithm (i.e., highly abstract concept), and its implementation is presented with visual clues that help the learners easily find the link between them. We tried to resolve the second issue, 'It becomes difficult to understand concepts and mathematical equations if learners cannot implement them.'

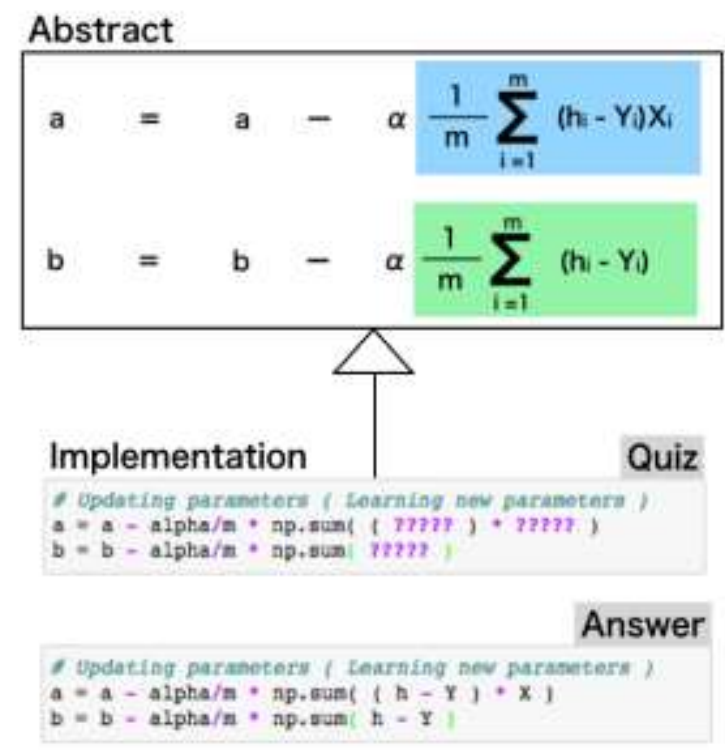

Figure 3: Visual clue between the abstraction and its implementation

\subsection{Managing the learning tasks with small agile steps}

In order to enable an agile learning method, it is necessary to provide a learning environment where the learners are allowed to work on the learning tasks in a try and error fashion. We 
provided Jupyter Notebook [18], an open-source environment, in our lecture designed for our study. Jupyter Notebook is composed of two types of cells. A code cell is where the code is written and executed, and a markdown cell is where the texts and images go in for the purpose of documenting the story attached to each learning task. The code put into a code cell can be executed anytime. Since code cells can be created as many as learners want, the learners can leave several code cells as the history of their work. This feature allows the learners to work on the learning tasks in a try and error fashion, and therefore it realizes the aim of the agile method. We tried to resolve the third issue, "Learners might lose their learning motivation if they cannot complete the given tasks."

\section{Evaluation Method \& Result}

We designed a basic AI course for non-technical adult learners as a blended course using the proposed teaching method. The summary of the evaluation method is depicted in Figure 4.

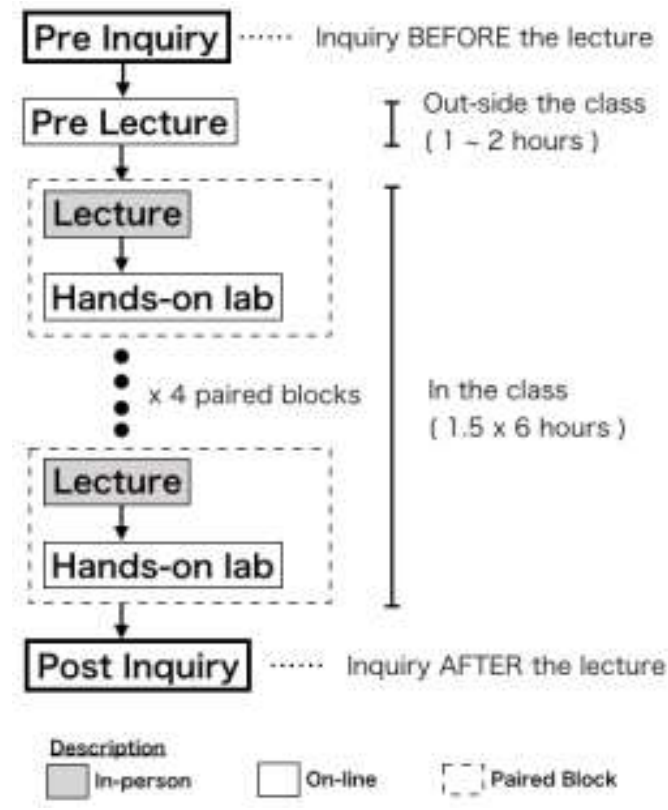

Figure 4: The flow of AI lecture (modified from Seya et al. [17])

Pre-Lecture: In this course, the participants are asked to take an online lecture to study the minimum amount of programming and mathematics required before the first lecture conducted in the class.

Lecture and Hands-on Labs: Lectures were provided in person, and hands-on labs were provided online using Jupyter Notebook. A hands-on lab is provided, followed by a lecture associated with it (i.e., they are paired). We created six paired blocks, and participants were asked to work on a small hands-on lab by themselves so that they could go through the course in a small step-by-step fashion and build a neural network by themselves by the end of the lecture.

Since each paired block was designed as a 1.5 hour-long block, it was possible to provide the whole lecture within a day. The titles of six lectures were as follows: 'History of Artificial Intelligence,' 'Linear regression,' 'Logistic regression,' 'Multi-Classification,' 'Image Representation,' and 'Neural Network.' 
By the quantitative analysis and the qualitative analysis over the participants in this lecture, we evaluated the effectiveness of the proposed teaching method. Responses were given on a fivepoint ordinal scale, ranging from - 2-"disagree," to +2-"agree," with 0 representing "neither agree nor disagree." Participants are asked to answer the same question before and after the lecture in the class (Figure 4).

Table 1: List of questionnaires

\begin{tabular}{|c|c|}
\hline & Effectiveness of Visual Method \\
\hline \multirow[t]{2}{*}{$\mathrm{e} 01$} & $\begin{array}{l}\text { Do you think the visual aids such as graphs and images, which you were provided as you } \\
\text { went through the class materials, supported your understanding of learning objectives? }\end{array}$ \\
\hline & Effectiveness of Agile Method \\
\hline \multirow[t]{2}{*}{$\mathrm{e} 02$} & Do you think it is a good style to take a lecture and do a hands-on lab in a parallel fashion? \\
\hline & Expected Success \\
\hline $\mathrm{q} 01$ & In the future, do you feel you will be able to understand AI deeply with confidence? \\
\hline $\mathrm{q} 02$ & In future, do you feel you will not be able to follow the lecture for understanding AI?* \\
\hline q03 & In the future, do you feel you will be able to understand the lecture for understanding AI? \\
\hline $\mathrm{q} 04$ & In the future, do you feel you will receive a good grade in understanding AI? \\
\hline q05 & In the future, do you feel you will be not able to understand AI? * \\
\hline \multirow[t]{2}{*}{$\mathrm{q} 06$} & In the future, do you feel you will be not good at understanding AI? * \\
\hline & Expected Value (Internal Value) \\
\hline q07 & Do you think understanding $\mathrm{AI}$ is interesting? \\
\hline q08 & Do you think the class for understanding $\mathrm{AI}$ is fun \\
\hline q09 & Do you think you like to study to understand AI? \\
\hline q10 & Do you think studying AI is not interesting? * \\
\hline q11 & Do you think studying AI is fun? \\
\hline q12 & Do you think it is fun to solve the problems to understand AI? \\
\hline \multirow[t]{2}{*}{$\mathrm{q} 13$} & Do you think you like to understand AI \\
\hline & Expected Value (Utility Value) \\
\hline q14 & Do you think it is important for you to be able to understand AI? \\
\hline q15 & Do you think understanding AI is very useful for your future? \\
\hline q16 & Do you think understanding AI does not have much impact on your future? * \\
\hline q17 & Do you think what you learn about AI in the class is important? \\
\hline q18 & Do you think what you learn about $\mathrm{AI}$ in the class is useful for the other subjects too? \\
\hline q19 & Do you think it is important for you to understand AI than others better? \\
\hline q20 & Do you think what you learned to understand AI is useful in daily life? \\
\hline q21 & Do you think it is important for you to understand AI deeply? \\
\hline q22 & Do you think it is very important for your future to have knowledge about AI? \\
\hline
\end{tabular}

*Negative Question

The expectancy-value theory [7] says that the expected success and value on the learning subject predict how well the learners will perform on the subject, and the value of the subject predicts if the learners will continue to make an effort on learning the subject. Therefore, we evaluated our teaching method based on this theory to evaluate if our goal is met or not. To create the list of question items to measure the expected success (Table 1), we took the question items created by Ichihara and Arai [19], which was created to measure the expected success and the expected 
values for the students learning mathematics, and replaced 'mathematics' with 'AI' to measure how confident the students are about understanding AI before and after the lecture.

In this study, in order to analyze the effectiveness of the agile method we deployed, we created a question item e 02 and asked its reason in a free format. We used the open-coding method [20] to analyze free descriptive answers with the following procedure:

Step 1: View the free answers and pick those are related to the three issues this teaching method tried to solve and learners' success expectation for understanding AI. The viewpoint set as "solving the three issues" and "learners' success expectation obtained in this course" for Affinity Diagram grouping, in order to evaluate solving the three issues and increasing learners' success expectation.

Step 2: Look for, from the aforementioned viewpoint, the descriptions relate to structuralizing with multiple viewpoints, and sort them into groups.

Step 3: Write titles for each group that summarizes the essence of the group, at a slightly higher level of abstraction (called "Open coding results" in this study)

In order to ensure the reliability of the open-coding result generated by the first author, we $\{1$ validated the result with an open-coding specialist [21].

\subsection{Profile of Participants}

The participants in this lecture were business professionals coming from a wide range of industries, ages, job roles, and different levels of programming skills. In this study, we define a business professional as a person who has a job in a company. Table 2 summarizes the profiles of participants.

Table 2: Profile of participants

\begin{tabular}{|l|l|}
\hline Job Role & $\begin{array}{l}\text { Number of } \\
\text { Participants }\end{array}$ \\
\hline Manager & 11 \\
\hline Clerical Work (Human Resource, General Affair, Account, Communication) & 14 \\
\hline Sales & 12 \\
\hline Marketing & 7 \\
\hline Strategic Marketing Planning & 11 \\
\hline Strategic Engineering Planning & 10 \\
\hline Engineer & 9 \\
\hline Other & 16 \\
\hline
\end{tabular}

\begin{tabular}{|l|l|l|l|l|l|l|l|l|}
\hline Age & $20 \sim 24$ & $24 \sim 29$ & $30 \sim 34$ & $35 \sim 39$ & $40 \sim 44$ & $45 \sim 49$ & $50 \sim 54$ & $55 \sim 59$ \\
\hline $\begin{array}{l}\text { Number of } \\
\text { Participants }\end{array}$ & 3 & 2 & 3 & 14 & 24 & 23 & 19 & 2 \\
\hline
\end{tabular}

\begin{tabular}{|l|l|l|l|l|}
\hline Programming Experience & No Experience & Entry level & Junior level & Senior level \\
\hline Number of Participants & 58 & 24 & 6 & 2 \\
\hline
\end{tabular}


From the 90 participants above we selected 75 target participants as non-technical adult learners by removing participants who played engineer role in the office and who had a junior or senior level of programming expertise because they were close to a technical professional in terms of their programming expertise although she or he served a non-technical role in the office. Furthermore, we removed all the participants who take the engineering role in the office even though they claimed themselves to belong to 'No Experience' and 'Entry level' because they might underestimate themselves.

\subsection{Evaluation Result: Effectiveness of Agile Method}

We evaluated the effectiveness of agile method by the question item e01, 'Do you think the visual aids such as graphs and images, which you were provided as you went through the class materials, supported your understanding of learning objectives?', and by the question item e02, 'Do you think it is a good style to take a lecture and do a hands-on lab in a parallel fashion?'. These questions items were asked to the participants after the lecture.

Table 3 is a summary of the results over the question items: $\mathrm{e} 01$ and e 02 . Table $\mathrm{V}$ is the result of the open coding to analyze the reason for the answer e 02 (i.e., the reason why the participants felt the agile method was effective).

Table 3: Participants' attitude about the visual and the agile method

\begin{tabular}{|l|l|l|l|l|l|}
\hline & Minimum & Maximum & Median & Average & Standard Deviation \\
\hline $\mathrm{e} 01$ & 0 & 3 & 3 & 2.533 & 0.704 \\
\hline $\mathrm{e} 02$ & -2 & 3 & 3 & 2.36 & 1.0 \\
\hline
\end{tabular}

Table 4: The open coding result about the reason why the agile method works for non-technical adult learners

\begin{tabular}{|l|l|}
\hline Open Coding Result & $\begin{array}{l}\text { Number of } \\
\text { Sentences }\end{array}$ \\
\hline Actual programming experience improves my understanding of the subject. & 34 \\
\hline $\begin{array}{l}\text { Doing hands-on labs as soon as its lecture is presented helps me understand } \\
\text { the lecture deeply. }\end{array}$ & 27 \\
\hline $\begin{array}{l}\text { Because the connection between the concept and what I'm doing in its } \\
\text { hands-on labs becomes clear. }\end{array}$ & 17 \\
\hline Above all, it is fun, and I can learn independently in this way. & 3 \\
\hline
\end{tabular}

\section{Evaluation Result: Teaching Method}

Table 5, Table 6 , and Table 7 are the summaries of a paired t-test over the question items: q01 q22 in Table 1, which were asked to the participants before and after the lecture. Table 5 shows how the participants' success expectation changed, Table 6 shows how the participants' expected value changed in terms of learner's internal value of AI, and Table 7 shows how the participants' expected value changed in terms of learner's utility value of AI. 
Table 5: Participants' success expectation change

\begin{tabular}{|c|c|c|c|c|c|c|c|c|}
\hline \multirow[b]{3}{*}{ ID } & \multicolumn{5}{|c|}{ Paired Differences } & \multirow[b]{3}{*}{$\mathrm{t}$} & \multirow[b]{3}{*}{$\mathrm{df}$} & \multirow[b]{3}{*}{ P Value (2-tailed) } \\
\hline & \multirow[b]{2}{*}{ Mean } & \multirow{2}{*}{$\begin{array}{l}\text { Std. } \\
\text { Dev. }\end{array}$} & \multirow{2}{*}{$\begin{array}{l}\text { Std. } \\
\text { Error } \\
\text { Mean }\end{array}$} & \multicolumn{2}{|c|}{$\begin{array}{l}\text { 95\% Confidence Interval } \\
\text { of the Difference }\end{array}$} & & & \\
\hline & & & & Lower & Upper & & & \\
\hline $\mathrm{q} 01$ & -1.35 & 1.19 & 0.138 & -1.62 & -1.07 & -9.79 & 74 & $0 * * *$ \\
\hline $\mathrm{q} 02$ & 1.17 & 1.78 & 0.206 & 0.764 & 1.58 & 5.71 & 74 & $0 * * *$ \\
\hline $\mathrm{q} 03$ & -1.2 & 1.52 & 0.175 & -1.55 & -0.85 & -6.86 & 74 & $0 * * *$ \\
\hline $\mathrm{q} 04$ & -1.4 & 1.22 & 0.141 & -1.69 & -1.12 & -9.94 & 74 & $0 * * *$ \\
\hline q05 & 0.97 & 1.60 & 0.185 & 0.605 & 1.34 & 5.26 & 74 & 0 *** \\
\hline $\mathrm{q} 06$ & 0.85 & 1.35 & 0.156 & 0.542 & 1.17 & 5.46 & 74 & 0*** \\
\hline
\end{tabular}

*** Significant at $\mathrm{P}<0.0001$

Table 6: Participants' expected value change (Internal Value)

\begin{tabular}{|c|c|c|c|c|c|c|c|c|}
\hline \multirow[b]{3}{*}{ ID } & \multicolumn{5}{|c|}{ Paired Differences } & \multirow[b]{3}{*}{$\mathrm{t}$} & \multirow[b]{3}{*}{ df } & \multirow[b]{3}{*}{ P Value (2-tailed) } \\
\hline & \multirow[b]{2}{*}{ Mean } & \multirow{2}{*}{$\begin{array}{l}\text { Std. } \\
\text { Dev. }\end{array}$} & \multirow{2}{*}{$\begin{array}{l}\text { Std. } \\
\text { Error } \\
\text { Mean }\end{array}$} & \multicolumn{2}{|c|}{$\begin{array}{l}95 \% \text { Confidence Interval } \\
\text { of the Difference }\end{array}$} & & & \\
\hline & & & & Lower & Upper & & & \\
\hline $\mathrm{q} 07$ & -0.21 & 0.859 & 0.099 & -0.411 & -0.02 & -2.15 & 74 & $0.035^{*}$ \\
\hline q08 & -0.49 & 0.991 & 0.114 & -0.721 & -0.27 & -4.31 & 74 & $0 * * *$ \\
\hline q09 & -0.48 & 1.07 & 0.124 & -0.726 & -0.23 & -3.89 & 74 & $0 * * *$ \\
\hline $\mathrm{q} 10$ & 0.253 & 0.807 & 0.093 & 0.068 & 0.439 & 2.72 & 74 & $0.008 *$ \\
\hline q11 & -0.36 & 1.022 & 0.118 & -0.595 & -0.13 & -3.05 & 74 & $0.003^{* *}$ \\
\hline q12 & -0.68 & 1.187 & 0.137 & -0.953 & -0.41 & -4.96 & 74 & $0 * * *$ \\
\hline q13 & -0.48 & 0.828 & 0.096 & -0.67 & -0.29 & -5.02 & 74 & $0 * * *$ \\
\hline
\end{tabular}

*** Significant at $\mathrm{P}<0.0001$, ** Significant at $\mathrm{P}<0.005, *$ Significant at $\mathrm{P}<0.05$

Table 7: Participants' expected value (Utility Value)

\begin{tabular}{|c|c|c|c|c|c|c|c|c|}
\hline \multirow[b]{3}{*}{ ID } & \multicolumn{5}{|c|}{ Paired Differences } & \multirow[b]{3}{*}{$\mathrm{t}$} & \multirow[b]{3}{*}{ df } & \multirow[b]{3}{*}{ P Value (2-tailed) } \\
\hline & \multirow[b]{2}{*}{ Mean } & \multirow{2}{*}{$\begin{array}{l}\text { Std. } \\
\text { Dev. }\end{array}$} & \multirow{2}{*}{$\begin{array}{l}\text { Std. } \\
\text { Error } \\
\text { Mean }\end{array}$} & \multicolumn{2}{|c|}{$\begin{array}{l}95 \% \text { Confidence Interval } \\
\text { of the Difference }\end{array}$} & & & \\
\hline & & & & Lower & Upper & & & \\
\hline q14 & -0.25 & 0.824 & 0.095 & -0.443 & -0.06 & -2.66 & 74 & $0.009 * *$ \\
\hline q15 & -0.07 & 0.777 & 0.09 & -0.245 & 0.112 & -0.74 & 74 & 0.46 \\
\hline q16 & 0.28 & 1.236 & 0.143 & -0.004 & 0.564 & 1.961 & 74 & 0.054 \\
\hline q17 & -0.19 & 0.833 & 0.096 & -0.378 & 0.005 & -1.94 & 74 & 0.056 \\
\hline q18 & -0.03 & 1.174 & 0.136 & -0.297 & 0.243 & -0.2 & 74 & 0.845 \\
\hline q19 & -0.17 & 1.245 & 0.144 & -0.46 & 0.113 & -1.21 & 74 & 0.232 \\
\hline q20 & -0.04 & 1.224 & 0.141 & -0.322 & 0.242 & -0.28 & 74 & 0.778 \\
\hline q21 & -0.15 & 0.896 & 0.103 & -0.353 & 0.059 & -1.42 & 74 & 0.16 \\
\hline $\mathrm{q} 22$ & 0 & 0.735 & 0.085 & -0.169 & 0.169 & 0 & 74 & 1 \\
\hline
\end{tabular}

** Significant at $\mathrm{P}<0.005$ 


\section{Discussion}

The effectiveness of the visual method and the effectiveness of the agile method for non-technical adult learners are shown in Table 3 as the results of question item e 01 and $\mathrm{e} 02$, respectively. Their highly positive average scores, 2.53 for e 01 and 2.36 for e 02 , suggest that both methods were well accepted by the participants and positively supported participants' learning process.

The reason why the participants thought the agile method we deployed in this lecture worked well for them was analyzed by the open-coding method. The agile practice of learn-by-doing is represented in the first category, 'Actual programming experience improves my understanding of the subject.', and the comments related to this category appeared 34 times. The agile practice of iterate-small-steps is represented in the second category, 'Doing hands-on practices as soon as its lecture is presented helps me understand the lecture deeply.', and the comments related to this category appeared 27 times. These results suggest that the agile method worked in the same way it works in software development.

The third category, 'Because the connection between the concept and what I'm doing in its handson practice becomes clear.', suggests that the participants understood abstract concepts and algorithms by actually implementing them. We could see that the agile method played an important role for participants to find and understand the link between concept and its implementation. The last category, 'Above all, it is fun, and I can learn independently in this way.', suggests that the adult learners were self-directed and enjoyed the learning process [22]. This is one of the desired effects that we planned to have in the lecture by introducing the agile method in our teaching method.

According to the expectancy-value theory, the expected success and the value the learners put on the learning subject predicts if the learners can successfully complete the learning process and if they continue to learn the subject by themselves in the future. The change in the expected success appears in Table 5 . All the paired differences in Table 5 were confirmed to be statistically significant in terms of the average value with $\mathrm{P}<0.0001$, which shows a very strong shift to the positive side. The change in the internal value (i.e., how much the learners feel the subject interesting and fun) appears in Table 6. All the paired differences on this table are also statistically significant, which indicates the increased interest in AI. The change in the utility value (i.e., how much the learners feel the subject useful) appears in Table 7 . While the statically significant change is found on q14, 'Do you think it is important for you to be able to understand AI?', the other items on the table does not indicate statically meaningful shift because the learners felt the usefulness in understanding AI before taking the lecture and they stayed the same after the lecture.

\section{Limitations and Future Work}

In this study, we did not explore implications related to age, gender, nationality. Although we confirmed the effectiveness of the use of stories, visual feedback and agile method for non-technical adult learners who want to get an authentic understanding of AI, we do not know other possible factors which engender positive changes in learners' attitude. We also did not explore the effectiveness of this method when it is provided in different types of learning environments, such as online. 


\section{Conclusion}

The purpose of this study was to propose the use of stories, visual feedback, and agile teaching method for non-technical adult learners who want to gain an authentic understanding of AI within a short time budget.

With the proposed method, we tried to overcome the following three issues: (1) The non-technical adults might not be able to understand programming at all. (2) It becomes difficult to understand concepts and mathematical equations if learners cannot implement them. (3) Learners might lose their learning motivation if they cannot complete the given tasks.

We designed and conducted an AI course with authentic programming tools and environment for non-technical adult learners as a blended course using the proposed teaching method. By the quantitative and qualitative analysis, we confirmed that non-technical adult learners had significantly changed their attitude in understanding AI from initially negative to positive $t$ in terms of expected success and expected value within a day-long time budge.

Further researches are needed for the following topics:

- Study how the proposed method can be implemented with scalability

- Study if the proposed method can be extended to the other subjects

- Reveal the effectiveness of the proposed teaching method for technical learners too

\section{References}

[1] P. K. Chilana et al., "Perceptions of non-CS majors in intro programming: The rise of the conversational programmer," in 2015 IEEE Symposium on Visual Languages and HumanCentric Computing (VL/HCC), Atlanta, GA, 2015, pp. 251-259, doi: 10.1109/VLHCC.2015.7357224.

[2] P. K. Chilana, R. Singh, and P. J. Guo, "Understanding Conversational Programmers: A Perspective from the Software Industry," in Proceedings of the 2016 CHI Conference on Human Factors in Computing Systems - CHI '16, Santa Clara, California, USA, 2016, pp. 1462-1472, doi: $10.1145 / 2858036.2858323$.

[3] A. Y. Wang, R. Mitts, P. J. Guo, and P. K. Chilana, "Mismatch of Expectations: How Modern Learning Resources Fail Conversational Programmers," in Proceedings of the 2018 CHI Conference on Human Factors in Computing Systems, New York, NY, USA, 2018, pp. 511:1511:13, doi: 10.1145/3173574.3174085.

[4] Y. Bosse and M. A. Gerosa, "Why is Programming So Difficult to Learn?: Patterns of Difficulties Related to Programming Learning Mid-Stage," SIGSOFT Softw. Eng. Notes, vol. 41, no. 6, pp. 1-6, Jan. 2017, doi: 10.1145/3011286.3011301.

[5] M. Butler and M. Morgan, "Learning challenges faced by novice programming students studying high level and low feedback concepts," p. 9, 2007. 
[6] A. Wigfield and J. S. Eccles, "Expectancy-Value Theory of Achievement Motivation," Contemporary Educational Psychology, vol. 25, no. 1, pp. 68-81, Jan. 2000, doi: 10.1006/ceps.1999.1015.

[7] B. \& Noble, "Computers and the World of the Future," Barnes \& Noble. [Online]. Available: $\mathrm{https}$ :/www.barnesandnoble.com/w/computers-and-the-world-of-the-future-martin-greenberger/1100660865. [Accessed: 11-Mar-2019].

[8] P.-H. Tan, C.-Y. Ting, and S.-W. Ling, "Learning Difficulties in Programming Courses: Undergraduates' Perspective and Perception," in 2009 International Conference on Computer Technology and Development, Kota Kinabalu, Malaysia, 2009, pp. 42-46, doi: 10.1109/ICCTD.2009.188.

[9] R. D. Pea and D. M. Kurland, "On the cognitive effects of learning computer programming," New Ideas in Psychology, vol. 2, no. 2, pp. 137-168, Jan. 1984, doi: 10.1016/0732118X(84)90018-7.

[10] D. B. Palumbo, "Programming Language/Problem-Solving Research: A Review of Relevant Issues - David B. Palumbo, 1990," Review of Educational Research, vol. 60, no. 1, pp. 65-89, Mar. 1990.

[11] U. Wilensky, C. E. Brady, and M. S. Horn, "Fostering computational literacy in science classrooms," Communications of the ACM, vol. 57, no. 8, pp. 24-28, Aug. 2014, doi: $10.1145 / 2633031$.

[12] E. Schanzer, K. Fisler, S. Krishnamurthi, and M. Felleisen, "Transferring Skills at Solving Word Problems from Computing to Algebra Through Bootstrap," in Proceedings of the 46th ACM Technical Symposium on Computer Science Education - SIGCSE '15, Kansas City, Missouri, USA, 2015, pp. 616-621, doi: 10.1145/2676723.2677238.

[13] B. L. Sherin, "A Comparison of Programming Languages and Algebraic Notation as Expressive Languages for Physics," International Journal of Computers for Mathematical Learning, vol. 6, no. 1, pp. 1-61, Jun. 2001.

[14] N. Kobayashi, A. Nakamoto, M. Kawase, F. Sussan, and S. Shirasaka, "What Model(s) of Assurance Cases Will Increase the Feasibility of Accomplishing Both Vision and Strategy?," Review of Integrative Business and Economics Research, vol. 7, no. 2, pp. 1-17, 2018.

[15] J. Spriggs, GSN - The Goal Structuring Notation: A Structured Approach to Presenting Arguments. Springer Science \& Business Media, 2012.

[16] M. Fowler and J. Highsmith, "The agile manifesto. Software Development," Software Development, vol. 9, no. 8, pp. 28-35, 2001.

[17] K. Seya, N. Kobayashi, and S. Shirasaka, "Method of Creating Story-based Lectures from a Past-to-present Perspective that Helps Non- Technical Adult Learners Understand AI," Review of Integrative Business and Economics Research, vol. 9, no. 1, pp. 16-45, 2019.

[18] “Project Jupyter.” [Online]. Available: https://www.jupyter.org. [Accessed: 13-Mar-2019]. 
[19] Ichihara M. and Arai K., "Moderator effects of meta-cognition: A test in math of a motivational model," Japanese Journal of Educational Psychology, vol. 54, no. 2, pp. 199-210, 2006, doi: 10.5926/jjep1953.54.2_199.

[20] N. Kobayashi, A. Nakamoto, and S. Shirasaka, "What is it to structuralize with multiple viewpoints by using Goal Structuring Notation (GSN)?," Int J Jpn Assoc Mgt Sys, vol. 10, no. 1, pp. 125-130, Dec. 2018, doi: 10.14790/ijams.10.125.

[21] N. Golafshani, "Understanding Reliability and Validity in Qualitative Research," The Qualitative Report, vol. 8, no. 4, pp. 597-607, 2003.

[22] G. Manning, "Self-Directed Learning: A Key Component of Adult Learning Theory," Business and Public Administration Studies, vol. 2, no. 2, p. 104, 2007. 